\title{
Tuberculosis of the skeletal system (bones, joints, spine and bursal sheaths)
}

\author{
By SM Tuli \\ Jaypee Brothers and Medical Publishers (P) Ltd.
}

This book has provided a scientific foundation to treat osteoarticular tuberculosis to Orthopedic surgeons in the developing world for the last three decades. It gives a clear insight to diagnose and treat this very old disease, which is known and described in the historical literature.

This is a basic as well as a reference book on tuberculosis of the bone and joint. Newer technology, imaging and subsequent research throws newer light on the understanding of the pathophysiology, diagnostics and treatment principles to improve the outcome of treatment.

Human immunodeficiency virus and multidrug resistance has compounded the management of osteoarticular tuberculosis.
This fourth edition has added serological tests and immune modulation for multidrug-resistant and therapeutically refractory cases. These issues have been covered with 25 newer images and 80 references. The whole book emphasizes on the "Correct treatment" that influences the life of the patients, family and the society at large.

I recommend this new edition to be read by one and all and as a reference book in libraries in an attempt to solve the menacing oldest infective disease, i.e. "Tuberculosis."

Anil K Jain

Department of Orthopaedics, UCMS and GTB Hospital, Dilshad Garden, Delhi - 110 095, India. E-mail: dranilkjain@gmail.com 